\title{
Non-White Migration, Welfare Levels, And The Political Process: A Reply
}

\author{
by Richard J. Cebula*
}

\section{INTRODUCTION**}

In a recent issue of this Review, Premus and Weinstein (7, p. 11) allege to "... correct the specification and identification errors in ..." a paper on welfare levels and non-white migration patterns which I (2) had earlier published in another journal. Premus and Weinstein (hereafter P-W) first critique my paper and then offer a "corrected" model upon which they base certain policy implications. The purposes of this reply are, first, to critique the model and results in the $\mathrm{P}-\mathrm{W}$ paper and, second, then to offer an alternative model on non-white migration and welfare.

\section{THE PREMUS-WEINSTEIN "CORRECTED” MODEL}

My original paper (2) consists of a two-equation model which is used to test the hypothesis that (a) non-white migrants (as a surrogate for migration of the poor) are attracted by high welfare levels and (b) welfare levels themselves are affected, through a political process, by non-white migration patterns. Premus and Weinstein (7, pp. 12-13) justifiably criticize my not using race-specific income and unemployment data. My use of median income in one equation and per capita income in another equation, while technically valid, is also justifiably criticized on other technical grounds because these variables are so highly correlated. The remaining criticisms by $\mathrm{P}-\mathrm{W}$ are fundamentally naive, largely irrelevant, and basically unsubstantiated, even by P-W's own results. These remaining criticisms by $\mathrm{P}-\mathrm{W}$ are addressed below.

As an alternative to my model in (2), Premus and Weinstein (7) offer the following:

(1) $\mathrm{X}_{1}=\mathrm{t}\left(\mathrm{X}_{2}, \mathrm{X}_{3}, \mathrm{X}_{4}, \mathrm{X}_{5}, \mathrm{X}_{6}, \mathrm{X}_{7}\right)$

(2) $\quad X_{2}=t\left(X_{1}, X_{8}, X_{9}, X_{10}\right)$

where:

$$
\begin{aligned}
& \mathrm{X}_{1}= \text { net migration rate of blacks, } 1960-1970 ; \\
& \mathrm{X}_{2}= \text { change in monthly aid per family with dependent } \\
& \text { children (AFDC), 1965-1970; }
\end{aligned}
$$

\footnotetext{
* Professor of Economics, School of Business Administration, Emory University.

** The author wishes to thank Pamela Brannen and Lisa Smith for helpful comments.
} 
$* \mathrm{X}_{3}=$ change in black median family income, 1960-1970;

$* * \mathrm{X}_{4}=$ black unemployment rate, 1960 ;

$* \mathrm{X}_{5}=$ net migration rate of blacks, 1950-1960;

$* * \mathrm{X}_{6}=$ median family income of blacks, 1959 ;

$* \mathrm{X}_{7}=$ normal monthly average temperature, 1941-1971;

$\mathrm{X}_{8}=$ total unemployment rate, 1960 ;

$* \mathrm{X}_{9}=$ change in percentage female heads of households, 1960-1970; and

$* \mathrm{X}_{10}=$ change in per capita income, 1960-1970.

where, relative to my initial paper (2), a single asterisk $(*)$ denotes a new variable and a double asterisk (**) denotes a changed variable.

Estimating the regression system corresponding to (1) - (2) by 2SLS, Premus and Weinstein (7) find the coefficients for both $\mathrm{X}_{2}$ in equation (1) and $\mathrm{X}_{1}$ in equation (2) to be positive, as argued in Cebula (2). However, they also find that, while non-white migration is a significant determinant of welfare levels (as hypothesized in Cebula (2)), welfare is not a significant determinant of non-white migration. Actually, the latter finding is rather novel. A review of the welfare-migration literature would clearly reveal that nearly all of the relevant regression models find non-white migration (or migration of the poor) to be positively and significantly influenced by welfare. The P-W results may in part be the result of multicollinearity. For instance, the zero-order correlation coefficient between AFDC and black income is very high, about +.68 . Similarly, the correlation between AFDC and variables $\mathrm{X}_{3}, \mathrm{X}_{5}$, and $\mathrm{X}_{7}$ may also be dampening some of the would-be effects of an AFDC variable. Apparently, Premus and Weinstein (7, p. 16) seem to "sense" multicollinearity problems: "... states which are experiencing greater increases in affluence are the states which offer greater increases in welfare payments." Unfortunately, they are unable to apply this possible sensitivity to their own model. Of course, they could have greatly helped the reader, and perhaps their own analysis, had they provided a correlation matrix.

In critizing my paper (2) for omitting "other" variables from the system, Premus and Weinstein (7) react by adding variables such as $\mathrm{X}_{3}$ (income change) and $\mathrm{X}_{7}$ (temperature). In the latter case, $\mathrm{P}-\mathrm{W}$ have chosen to add a variable to their system which, in their own analysis, turns out to be statistically insignificant at any acceptable level (actually, they have four such variables in their system). Along this line, one must wonder why they omitted the variable "percent black," which has so often been found to be a significant determinant of black migration.

In introducing the income-change variable $\left(\mathrm{X}_{3}\right), \mathrm{P}-\mathrm{W}$ aim to allow for 
"income expectations." This particular approach, however, is now dated. Greenwood (4, p. 519) has already dealt with this issue and demonstrated that simultaneity bias results from the use of "... variables relating to a change... to explain migration ... over the same interval of time for which the changes are defined." Moreover, Cebula and Vedder (3) have more recently shown that including the income-change variable introduces a serious simultaneity problem, one which may necessitate the addition of a separate, new equation to the regression system. Since P-W do not add such an equation, we can only infer that their coefficients may be seriously biased.

In appraising the Premus-Weinstein (7) model, results, and policy discussion, one must wonder whether - in attempting to learn from research and to extend that research - they could have conceived of using the welfare level as a variable in lieu of the change in welfare. This would have given them a chance to make a meaningful improvement in the analysis. Given the fact that P-W make policy inferences from their analysis, inferences which relate to welfare levels per se (not changes therein), one is left perplexed that it apparently never occurred to them to examine welfare levels in order to derive a policy proclamation. The simple fact of the matter is that welfare levels have generally been found to affect (distort) migration of the poor. The $\mathrm{P}-\mathrm{W}$ results to the contrary derive from a single model (one plagued by multicollinearity and simultaneity bias) dealing with a very non-standard welfare variable. Their approach is naive and spanks of the "strawman" approach. Moreover, their model-construction and policy discussion bring further doubt and concern in view of P-W's total neglect of the recent literature on migration and living costs, a literature (see, for example, Renas and Kumar (8)) which could eventually lead to a policy of welfare uniformity in real terms.

\section{AN ALTERNATIVE MODEL}

To take issue with the Premus-Weinstein (7) conclusion that non-white migration is not affected by the current welfare system, the following model is offered:

$$
\mathrm{Mi}=\mathrm{Mi}(\text { Westi, Yi, AFDCi) }
$$

where $\mathrm{Mi}=$ net non-white in-migration to state i, 1960-1970

Westi = dummy variable to indicate a "western" state (related to this variable, see the discussion in Cebula (1))

$$
\mathrm{Yi}=1959 \text { median income level in state } \mathrm{i}
$$

AFDCi $=$ AFDC level per recipient family in state $\mathrm{i}, 1971$ 
Data were obtained from various issues of the Statistical Abstract of the United States. On the basis of previous studies by Cebula (1), Pack (6), and others, it is expected that

$$
\frac{\partial \mathrm{Mi}}{\partial \mathrm{Westi},} \frac{\partial \mathrm{Mi}}{\partial \mathrm{Yi}_{1}} \frac{\partial \mathrm{Mi}}{\partial \mathrm{AFDCi}}>0
$$

Estimating (3) in linear form by OLS yields:

$$
\mathrm{Mi}=-68.84390+7.54158 \text { Westi }+0.02685 \mathrm{Yi}+0.10574 \text { AFDCi, }
$$

$$
\mathrm{DF}=35, \quad \mathrm{R}^{2}=.75, \text { F-ratio }=34.11
$$

where terms in parentheses are standard errors.

The result of greatest relevance here is that welfare appears to be a highly significant determinant of non-white migration. This is but one of many dozens of such models which find this very same result. Moreover, this result lends yet more support to my recent reply (1) to JonesHendrickson (5) on my original paper (2).

\section{CONCLUSION}

The "bottom line" is that Premus and Weinstein (7) allege to "extend" my model and, on the basis of a single and less-than-sound model of their own, choose to attack both my paper (2) and the increasingly widespread notion of introducing a uniform welfare system. At the very minimum, however, $\mathrm{P}-\mathrm{W}$ have naively and crudely attacked this problem and vastly overstated the importance of their results.

\section{REFERENCES}

1. Cebula, R. J., "Non-white Migration, Welfare, and Politics: A Re-examination," Public Choice, Vol. 33, No. 4, 1978, pp. 135-137.

2. Cebula, R. J., "A Note on Non-white Migration, Welfare Levels, and the Political Process," Public Choice, Vol. 28, No. 4, 1978, pp. 117-119.

3. Cebula, R. J. and Vedder, R. K., "Migration, Economic Opportunity, and the Quality of Life: Reply and Extension," Journal of Regional Science, Vol. 16, No. 1, 1976, pp. 113-115.

4. Greenwood, M. J., "Simultaneity Bias in Migration Models: An Empirical Examination," Demography, Vol 12, No. 3, 1975, pp. 519-536.

5. Jones-Hendrickson, S. B., "A Note on Non-white Mi- gration: Welfare Levels and the Political Process: A Comment," Public Choice, Vol. 33, No. 4, 1978, pp 131-134.

6. Pack, J., "The Determinants of Migration to Central Cities," Journal of Regional Science, Vol. 13, No. 2, 1973, pp. 249-260.

7. Premus, R. and Weinstein, R., "Non-white Migration Welfare Levels, and the Political Process: Some Additional Results," Review of Regional Studies, Vol. 7, No. 1, 1977, pp. 11-20.

8. Renas, S. and Kumar, R., "The Cost of Living, Labor Market Opportunities, and the Migration Decision: A Case of Misspecification?" Annals of Regional Science, Vol. 12, No. 2, 1978, pp. 95-104. 